\title{
Test review of Iranian university entrance exam: English Konkur examination
}

\author{
Ali Khodi ${ }^{1,2^{*}}$, Sayyed Mohammad Alavi ${ }^{1}$ and Hossein Karami ${ }^{1}$
}

\footnotetext{
* Correspondence: Ali.khodi@ut.ac.ir ${ }^{1}$ University of Tehran, Tehran, Iran ${ }^{2}$ University of Neyshabur,

Neyshabur, Iran
}

\begin{abstract}
The present paper appraises a standardized test, the entrance exam of Iranian universities, known as "Konkur" that is administered annually as a means of gaining admission to higher education in Iran. This norm-referenced test is administered for students majoring in mathematics, experimental sciences, and humanities whose scores along their weighted GPAs in the last 3 years of high school are used as indicators of students' rank. Based on the rank achieved, they would find the opportunity to select the highly regarded university for their education. Due to the importance of such a high-stake test which may bring about social and long-time consequences for the participants, the present paper tries to evaluate the test and its psychometrics aspects. It is ostensible that the exam provides a limited situation for measuring the participants "knowledge of language" rather than their "knowledge about language." Therefore, the dimensionality and validity of the test are debatable. Thus, the present review tries to characterize Konkur examination and discusses the rooms for untouched aspects for the betterment of its quality.
\end{abstract}

Keywords: Evaluation, Iranian university English exam, Konkur examination, Test review, Validity

\section{General description}

The Iranian National University Exam, known as the UEE, is called Konkur examination in Iran. It is probably the changed form of the French term "concours," which refers to the process of sourcing, screening, and selecting people for different purposes. UEE is administered in three majors including foreign languages. This is a large scale high-stake standardized test of the English language initially administered in 2002 for the entire country (Razmjo, 2006). The test administration is done through the cooperation between the National Organization of Educational Testing of Iran (NOET) and major universities of each city throughout the county. This is a very competitive exam for those who wish to enter public tuition-free universities (Hosseini, 2007). It is a comprehensive test, which integrates the assessment of reading comprehension ability, vocabulary knowledge, the knowledge of language functions, the ability of answering cloze tests as well as knowledge of grammar and structure of English into one multiple choice test. This test makes inferences about the English ability of the participants. All topics addressed in the test could be found in the books introduces as the main

(c) The Author(s). 2021 Open Access This article is licensed under a Creative Commons Attribution 4.0 International License, which permits use, sharing, adaptation, distribution and reproduction in any medium or format, as long as you give appropriate credit to the original author(s) and the source, provide a link to the Creative Commons licence, and indicate if changes were made. The images or other third party material in this article are included in the article's Creative Commons licence, unless indicated otherwise in a credit line to the material. If material is not included in the article's Creative Commons licence and your intended use is not permitted by statutory regulation or exceeds the permitted use, you will need to obtain permission directly from the copyright holder. To view a copy of this licence, visit http://creativecommons.org/licenses/by/4.0/. 
sources of instruction in the school years in Iran. The test is considered to be a normreferenced test that is designed to evaluate the students' ability. Mainly, the examinees are native speakers of Farsi who only sit for the test in the standard exam centers, within and outside of the country, approved by the NOET.

At the time that the test was administered for the first time, the main focus of language instruction was on enabling students in terms of reading comprehension ability because they were supposed to be able to cope with the demands of reading technical texts at university. Thus, we can see that the focus of this test was given to reading comprehension, structure of the language, grammar, and vocabulary (Farhady, 1985). After 18 years the structure of the test is remained almost intact. Recently, the course books are reviewed and revised and we believe that a new test format is required to assess the communicative ability of students rather than purely memorized grammar and vocabulary.

You can find the test pamphlet that is distributed among the participants in four codes (A, B, C, D). All pamphlets, even in different codes, present the same questions, the same sub-sections, and the same sequence of sub-sections; the only difference in these codes is either the sequence of items or the sequences of the options for items form one person to another. That is, although the examinees answer the same questions, they receive the questions in diffrent orders. The time of administration is 105 mins. All items are dichotomously scored. A correction for guessing is also applied whereby, three incorrect answers would remove one of the correct answers. The number of the questions is 70 presented in sub-sections, namely, grammar (10 items), vocabulary (15 items), sentence structure (5 items), language functions (10 items), cloze test (15 items), and reading comprehension presented as three separate texts (15 items). Statistically speaking, we can see that the test content is not distributed among different section and skills equally; it is as following: about $27.15 \%$ for structure and grammar, $34.28 \%$ for vocabulary, and 38.57 for reading comprehension (Razmjo, 2006).

\section{Test formats}

Based on the content of the books presented to the students at high schools, the test is designed and accommodates six sections as following:

\section{Grammar section}

This section includes 10 questions asking about English grammar. The questions are presented in the form of incomplete sentences that should be completed by the option that is to be selected by the students; the options could be phrases, words, prepositions, or verbs. In terms of the sequences of question, there is no pre-determined rule and they are sequenced randomly for each participant rather than on a regular basis that is the same for all participants. Sometimes two grammatical rules are mixed in one question that seems to be very complex for the students to detect the idea behind the question and find the correct answer.

\section{Vocabulary}

In this part, 15 questions are presented in the form of incomplete sentences. The students should select the best option for the completion of the sentence meaning. Among 
the options provided for the participants the correct answer was instructed previously within the calssroom context, however, the distracts may be new words for them. The part of speech of the options may differ across questions but it is tried to be the same among the options of each single item in order to prevent the possibility of random guessing on the part of the participants.

\section{Sentence structure}

In this part, there are 5 questions; each option of the question presents a sentence and the participants should select the option in which there is no grammatical mistake based on the stem of the question. Mainly, the sentences are long in the form of compound and complex sentences and the mistake could be presented in any component of the sentence.

\section{Language functions}

In this part, several conversations (mainly does not exceed 3 ) are written and it is composed of 10 questions. The participants should complete the conversations with the best answers from the options. The correct answer should serve as a complement for the conduction of the function that is happening between two sides of the conversation.

\section{Cloze test}

In this part, participants should read a passage in which there are 15 blanks (mainly occurs at a regular number distance, for instance every ten words) and select the option which completes the sentence best. Since the blanks are presented in one text, misunderstanding or failure in finding the correct answer of one blank may lead or mislead the students to slect the proper option for the next blanks.

\section{Reading section}

Each test has three reading comprehension texts whose length ranges from 350 to 500 words covering a wide range of topics such as academic, scientific, and social issues. For each text, there are 5 multiple choice items asking about the content of the text, meaning of the vocabulary, and sentence interpretations.

\section{Test qualities and psychometrics aspects}

\section{Reliability}

Due to the importance of the test consequences, the Konkur examination constructors should try their best to meet all the necessary conditions for the test reliability. The quality and number of the items stress that the objectivity of measurement is seriously considered resigned to the fact that a sufficient number of items $(\mathrm{N}=70)$ were presented all in the multiple choice format and were assessed through machine-scoring which is a reliable scoring procedure (Roberts, Altenberg, \& Hunter, 2020). We believe that the major concerns for reliability are the imbalanced number of items in each sub-section, the equal weight for the selection of wrong option in different subsection, and the interference of the skills in sections such as cloze test or grammar. The analyses that we run on internal consistency of the test shows that the level of reliability is not equal among different subsections partly due to the unequal number of items included in diffrent sections and it 
ranges for the lowest part belonging to grammar to the highest level which belongs to sentence structure section.

\section{Generalizability and dependability of findings}

Another concern in terms of reliabilty is the issue of dependability of findings and generalizability of the results. How is this possible to be sure that the outcome of the test is the real performance of the participants? Conceptually, dependability means how much the results of a test show the intended level of the construct we wanted to measure. The use of neutral texts and sentences in this test shows that the developers were aware of the issue and they tried to prevent the existence of any potential bias in the function of items. About the generalizability of the results, we should be aware that the participants were all Iranian students, and the content was taken from the books in high-school; therefore, the findings could be generalized to similar contexts of the country of administration rather than an international level. Khodi (2020) ran a generalizability analysis on a sample of 5000 examinees and reported that and $86 \%$ of the total variance can be explained by individuals, which is a high degree of reliability of the test. Since, in addition to the gender of the participants, their major was different; they examined the potential contribution of major to the performance of students. It is reported that the interaction of individuals' fields of study and the overlapping questions in the test sections caused an error of about $1.5 \%$. It shows that the national entrance examination does not have a bias against any group of participants with different educational backgrounds.

\section{Validity}

As an academic test that is designed to assess the English level of test takers, it should enjoy some certain qualities the most important of which is believed to be validity. Based on Messick (1989) and Bachman (1990) validity accommodates a wider range of concepts including construct validity, content representativeness, and criterion-related validity. For the present test, validity means measuring what the test is supposed to measure while we believe that the social aspect of validity (Chalhoub, 2016) should be added to this old definition. We believe that no test could be considered valid outside of the specific use and context it is designed for (Messick, 1989). Thus, in proceeding some points related to the validity of the test are mentioned and explained.

We can see in the nature and structure of the question in the test that in spite of the construct definition of language proficiency, Konkur designers found it difficult to fully operationalize it due to the constraints and considerations of other test qualities to be manifested practically. For instance, speaking, writing and listening were not accommodated in the Konkur examination on account of the vast regional differences of participants due to accessibility issues to proper instruction. The exclusion of these skills is due to the the subjectivity in scoring these productive skills which may would pose some concerns in the matter of validity and reliability.

Overall, we believe that the construct of academic English was operationalized as the reading, grammar, and vocabulary skills that are critical to success of a first year student at university, or potentially it is the impact of needing such skills which at universities that has led to a test with such a format. It seems that the Konkur examination does not enjoy 
a full representation of construct validity as there is a wide gap between the intended curriculum and the test.

\section{Factor structure of the test and test dimensionality}

It is not clearly stated that the construct of measurement, that is language proficiency, is defined as a unidimensional of multidimensional construct. The the form and content of the test accentuate that there are several dimensions for the test, but on the other hand the sum-up procedure of scoring shows that no weighted score is dedicated to these dimensions and all are taken into account similarly. Even the difficulty of items does not contribute to the calculation of the final score of the participants. It means that answering a very difficult question would bring the same score as answering an easy question will bring. We suggest that for such a high-stake test with major social and life-long consequences the application of weighted scores and item difficulty level to the scoring procedure because it would increase the quality and dependability of the results. In the scoring procedure, in addition to what we stated, we can find another major concern. In spite of the fact that there is a wide range of item response theory models such as bifactor, higher-order or unidimensional models are taken as the basic framework of analysis, unfortunately in the scoring procedure of the test we could find no sign of using these models in validation procedure of the finding. In an independent study we made a comparison of these models and checked if the nature of language in this test is multidimensional or unidimensional. We found that the factor structure of language proficiency is best explained through the testlet model rather than being measured through the bifactor model (Alavi, Karami, \& Khodi, in press).

\section{Impact and washback}

It is believed that "testing is never a neutral process and always has consequences" (Stobart, 2003, p. 140). Evaluation of washback is a complex and multi-dimensional act that does not exist naturally and is taken as the the aftereffect of teachers, educators, or other factors' contribution in the test-taking procedure (Alderson \& Wall, 1993; Bailey, 1996; Cheng \& Falvey, 2000; Spratt, 2005). For the present test in particular, the washback effect occurs due to the fact that its structure is in practice a centralized, measurement-driven system whose orientation is bound to the teachersdominated classes, textbooks and testing impact (Ghorbani \& Neissari, 2015). Although the great emphasis for washback is suggested for communicative- oriented methods, and it is stressed that tests should explicitly be designed to bring positive washback (Cheng, Watanabe, \& Curtis, 2004), apparently in Iran this occurs for a reading-oriented test. Therefore, very few Iranian students finish high school with the ability to speak English effectively in spite of mastering the prescribed textbooks (Farhady, Jafarpoor, \& Birjandi, 1994), and English instruction in most of the Iranian academic situations seems to be ineffective and impractical (Hosseini, 2007).

In Iran, it was found that that the EEU negatively and implicitly influences English teachers for instruction of the content and format of the test (Salehi \& Yunus, 2012) and regarding the UEE format and importance, students potentially spend more time on grammatical structures, vocabulary, and reading than writing, pronunciation, speaking, and listening exercises (Farhady et al., 1994; Ghorbani, 2012). The ultimate 
objectives of the EFL program stay to be outlined that has led to different repercussions over the various periods of the educational program including assessment programs. The large scales and high s-stake test named Konkur functions alike an agreement among the instructors for deciding about the material of instruction, and its negative impacts known as washback and the implementation of the actual curriculum fails (Jahangard, 2007). This exam is extremely important not only to students and their parents but also to the larger society and the whole society is affected by its impacts. For instances, the traffic limitations are changes in the administration day and many parents wait outside the administration centers until to the end of the exam. As this importance accentuates, many non-governmental institutes have started to present the simulated exams, supplementary classes, and books for students to achieve the utmost skill for taking the test, a procedure that starts even starts almost 3 years before the test. Teachers are also influenced by the Konkur and try to adapt their instruction with the hidden curriculum and students' needs and even preferences.

\section{Clarity of the test}

The information that is distributed by test administration board aims at providing transparency the test configuration, test time, and format. In this particular case, the Konkur examination, such information is always published, disambiguated, and clarified. It is believed that the content presented in the textbooks would suffice mainly the needs of some students and for achieving higher ranks in the Konkur and having a good command of English; a supplementary sources are needed which fundamentally differ among the students of different schools and regions and this hidden syllabus is never determined and there is no consensus about it (Salehi \& Zamanian, 2012).

\section{Conclusion}

UEE enjoys a well-situated presentation of the content instructed and addresses the curriculum in a comprehensive manner. Although the washback looks somehow deconstructive, it could be reestablished with regards to the new course books and the priorities that have been newly accepted and changed. Challenges remain, inevitably, in terms of overlooking listening, writing, and speaking could be resolved possibly through addition of the new contents to the instructional curriculum and new test format. The construct irrelevant variance also may exist but could be suppressed by application of weighted scores and adding new variables such as applying students' educational background. The remaining concerns should be resolved once a consensus achieved about the definition of the constructed that is assessed basing in the test and new technological tools could be used in the assessment procedure. One major reason that some participants fail in the exam is the incompatibility of the nature of the items of the test with the item format, for instance, assessing the communicative ability of the participants through filling the blank of a conversation. The overall analysis of UEE depicts that although the context of the test and the content are in accordance, the nature is not a good indicator of participants real language ability due to lack of some important language skills in the test. Drawing on the social and life-time consequences of the test in Iranian society, it is promising that a well-deserved number of research studies evaluate UEE and provide suggestion for its betterment. 


\section{Appendix 1}

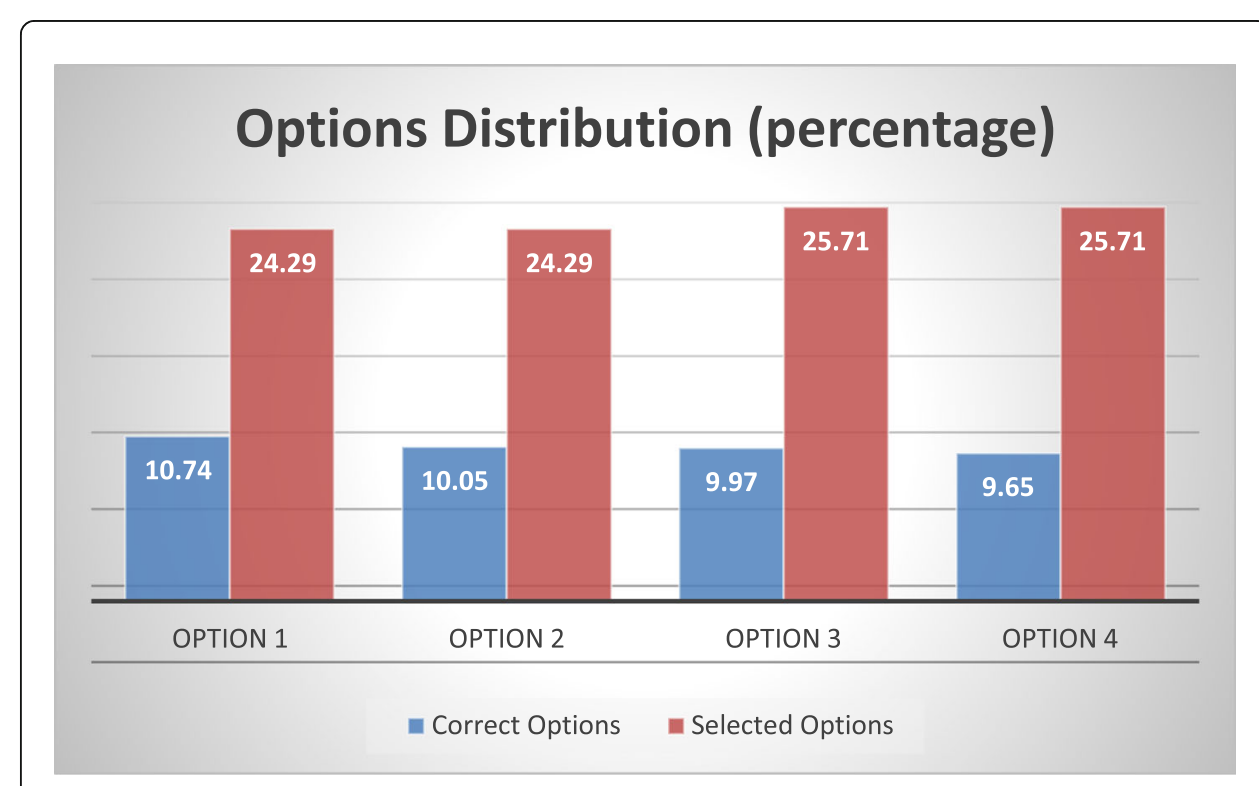

Fig. 1 Distribution of correct response and selected responses among options

\section{Appendix 2}

Table 1 Construct reliability and validity

\begin{tabular}{lllll}
\hline Dimension & Cronbach's alpha & rho_A & Composite reliability & Average variance extracted (AVE) \\
\hline General factor & 0.833 & 0.883 & 0.853 & 0.104 \\
Cloze test & 0.540 & 0.650 & 0.673 & 0.161 \\
Function & 0.507 & 0.562 & 0.684 & 0.196 \\
Reading & 0.594 & 0.669 & 0.711 & 0.167 \\
Grammar & 0.346 & 0.536 & 0.517 & 0.173 \\
Structure & 0.168 & 0.315 & 0.503 & 0.248 \\
Vocab & 0.584 & 0.672 & 0.687 & 0.166 \\
\hline
\end{tabular}




\section{Appendix 3}

Table 2 IRT analysis and dimensionality assessment

\begin{tabular}{|c|c|c|c|c|c|c|}
\hline \multirow[t]{2}{*}{ Item } & \multicolumn{2}{|c|}{ Unidimensional } & \multicolumn{2}{|c|}{ Bifactor } & \multicolumn{2}{|c|}{ Testlet } \\
\hline & $\overline{x^{2}}$ & Probability & $\overline{x^{2}}$ & Probability & $\overline{x^{2}}$ & Probability \\
\hline 1 & 75.29 & 0.0001 & 72.59 & 0.0001 & 19.72 & 0.0002 \\
\hline 2 & 24.4 & 0.0179 & 25.16 & 0.0141 & 13.07 & 0.0703 \\
\hline 3 & 20.22 & 0.0095 & 21.66 & 0.0056 & 7.9 & 0.0952 \\
\hline 4 & 25.42 & 0.0625 & 27.12 & 0.0401 & 4.1 & 0.3937 \\
\hline 5 & 60.38 & 0.0001 & 70.59 & 0.0001 & 9.6 & 0.0222 \\
\hline 6 & 28.61 & 0.0118 & 28.4 & 0.0079 & 22 & 0.0012 \\
\hline 7 & 39.95 & 0.0051 & 37.96 & 0.0089 & 21.24 & 0.0194 \\
\hline 8 & 25.34 & 0.1884 & 24.99 & 0.1603 & 19.52 & 0.034 \\
\hline 9 & 25.85 & 0.0039 & 24.86 & 0.0031 & 6.99 & 0.0304 \\
\hline 10 & 18.48 & 0.3611 & 18.76 & 0.2807 & 13.26 & 0.103 \\
\hline 11 & 48.13 & 0.0001 & 46.59 & 0.0001 & 30.84 & 0.0001 \\
\hline 12 & 35.76 & 0.0019 & 36.25 & 0.0016 & 8.06 & 0.1529 \\
\hline 13 & 15.58 & 0.3417 & 15.99 & 0.249 & 12.81 & 0.0766 \\
\hline 14 & 55.6 & 0.0001 & 56.17 & 0.0001 & 44.71 & 0.0001 \\
\hline 15 & 88.4 & 0.0001 & 80.13 & 0.0001 & 20.09 & 0.0012 \\
\hline 16 & 23.92 & 0.0208 & 25.1 & 0.0051 & 11.95 & 0.0629 \\
\hline 17 & 28.48 & 0.0123 & 29.32 & 0.0094 & 14.43 & 0.0711 \\
\hline 18 & 82.43 & 0.0001 & 69.5 & 0.0001 & 13.2 & 0.0042 \\
\hline 19 & 38.59 & 0.0012 & 37.29 & 0.0011 & 8.75 & 0.1876 \\
\hline 20 & 74.45 & 0.0001 & 63.45 & 0.0001 & 38.5 & 0.0001 \\
\hline 21 & 18.35 & 0.1909 & 18.08 & 0.1542 & 7.42 & 0.2856 \\
\hline 22 & 49.08 & 0.0003 & 48.4 & 0.0004 & 29.94 & 0.0002 \\
\hline 23 & 22.47 & 0.0693 & 22.48 & 0.0482 & 13.92 & 0.0524 \\
\hline 24 & 25.21 & 0.0216 & 26.18 & 0.0101 & 9.59 & 0.1428 \\
\hline 25 & 40.38 & 0.0001 & 45.9 & 0.0001 & 14.81 & 0.002 \\
\hline 26 & 59.15 & 0.0001 & 63.82 & 0.0001 & 22.28 & 0.0001 \\
\hline 27 & 10.89 & 0.8167 & 10.7 & 0.7744 & 12.32 & 0.1954 \\
\hline 28 & 49.23 & 0.0001 & 49.62 & 0.0001 & 16.99 & 0.0488 \\
\hline 29 & 25.43 & 0.1132 & 25.59 & 0.082 & 19 & 0.0884 \\
\hline 30 & 27.26 & 0.0985 & 27.33 & 0.0728 & 13.76 & 0.088 \\
\hline 31 & 27.54 & 0.0505 & 28.85 & 0.0501 & 13.56 & 0.1935 \\
\hline 32 & 84.17 & 0.0001 & 85.94 & 0.0001 & 43.32 & 0.0001 \\
\hline 33 & 56.35 & 0.0001 & 58.48 & 0.0001 & 17.26 & 0.004 \\
\hline 34 & 23.51 & 0.3166 & 23.9 & 0.1994 & 9.51 & 0.3933 \\
\hline 35 & 53.4 & 0.0001 & 55 & 0.0001 & 24.18 & 0.0005 \\
\hline 36 & 24.43 & 0.1795 & 25.3 & 0.1506 & 6.51 & 0.6889 \\
\hline 37 & 41 & 0.0001 & 42.57 & 0.0001 & 28.3 & 0.0001 \\
\hline 38 & 18.31 & 0.0744 & 18.75 & 0.0655 & 8.27 & 0.3113 \\
\hline 39 & 37.26 & 0.0007 & 39.07 & 0.0001 & 25.83 & 0.0005 \\
\hline 40 & 15.35 & 0.5007 & 17.44 & 0.3595 & 13.13 & 0.1072 \\
\hline 41 & 65.08 & 0.0001 & 65.61 & 0.0001 & 33.08 & 0.0001 \\
\hline 42 & 28.35 & 0.0568 & 32.59 & 0.0186 & 12.23 & 0.1407 \\
\hline
\end{tabular}


Table 2 IRT analysis and dimensionality assessment (Continued)

\begin{tabular}{|c|c|c|c|c|c|c|}
\hline \multirow[t]{2}{*}{ Item } & \multicolumn{2}{|c|}{ Unidimensional } & \multicolumn{2}{|c|}{ Bifactor } & \multicolumn{2}{|c|}{ Testlet } \\
\hline & $\overline{x^{2}}$ & Probability & $\overline{x^{2}}$ & Probability & $\overline{x^{2}}$ & Probability \\
\hline 43 & 34.78 & 0.0042 & 35.21 & 0.0014 & 19.38 & 0.0129 \\
\hline 44 & 15.49 & 0.4909 & 15.41 & 0.4243 & 5.99 & 0.4252 \\
\hline 45 & 64.69 & 0.0001 & 64.96 & 0.0001 & 35.73 & 0.0001 \\
\hline 46 & 36.11 & 0.0102 & 35.69 & 0.0077 & 17.03 & 0.0092 \\
\hline 47 & 25.72 & 0.058 & 26.99 & 0.0192 & 16.91 & 0.0179 \\
\hline 48 & 37.82 & 0.0026 & 37.71 & 0.0017 & 20.04 & 0.0027 \\
\hline 49 & 18.15 & 0.1996 & 18.15 & 0.1515 & 11.14 & 0.084 \\
\hline 50 & 18.47 & 0.4265 & 18.55 & 0.4215 & 11.75 & 0.1621 \\
\hline 51 & 25.22 & 0.1925 & 26.42 & 0.0904 & 14.39 & 0.072 \\
\hline 52 & 33.87 & 0.0007 & 34.41 & 0.0003 & 12.38 & 0.0299 \\
\hline 53 & 14.33 & 0.5024 & 14.97 & 0.382 & 11.14 & 0.1323 \\
\hline 54 & 45.02 & 0.0001 & 44.56 & 0.0001 & 14.89 & 0.0108 \\
\hline 55 & 33.21 & 0.0106 & 36.23 & 0.0027 & 9.08 & 0.3372 \\
\hline 56 & 26.26 & 0.1569 & 26.42 & 0.0902 & 14.72 & 0.0986 \\
\hline 57 & 17.07 & 0.2516 & 17.51 & 0.1765 & 5.56 & 0.4754 \\
\hline 58 & 45.74 & 0.0001 & 45.26 & 0.0001 & 20.66 & 0.0001 \\
\hline 59 & 31.64 & 0.0111 & 32.97 & 0.0029 & 23.01 & 0.0001 \\
\hline 60 & 33.27 & 0.0015 & 33.32 & 0.0009 & 19.62 & 0.0032 \\
\hline 61 & 29.57 & 0.0573 & 29.58 & 0.0416 & 19.75 & 0.0195 \\
\hline 62 & 48.38 & 0.0004 & 48.58 & 0.0002 & 22 & 0.0088 \\
\hline 63 & 18.68 & 0.5443 & 19.06 & 0.39 & 10.26 & 0.4195 \\
\hline 64 & 13.37 & 0.5751 & 13.54 & 0.4859 & 16.02 & 0.0663 \\
\hline 65 & 25.85 & 0.056 & 26.62 & 0.0319 & 11.34 & 0.1827 \\
\hline 66 & 22.74 & 0.1206 & 21.78 & 0.1134 & 14.82 & 0.0383 \\
\hline 67 & 18.73 & 0.2254 & 18.71 & 0.1319 & 23.35 & 0.0003 \\
\hline 68 & 47.3 & 0.0001 & 48.86 & 0.0001 & 18.57 & 0.0173 \\
\hline 69 & 21.79 & 0.2409 & 22.82 & 0.1547 & 13.57 & 0.0935 \\
\hline 70 & 36.91 & 0.0022 & 37.22 & 0.0012 & 21.84 & 0.0094 \\
\hline
\end{tabular}

\section{Abbreviations}

UEE: The Iranian National University entrance exam; NOET: The National Organization of Educational Testing :

EFL: English as foreign language

\section{Acknowledgements}

We thank the editor and reviewers.

\section{Authors' contributions}

All authors had the same contribution. The author(s) read and approved the final manuscript.

\section{Funding}

We received no funding.

\section{Availability of data and materials}

The data will be available upon request.

\section{Declaration}

Competing interests

We have no conflict of interest. 
Received: 7 February 2021 Accepted: 13 May 2021

Published online: 12 July 2021

\section{References}

Alavi, S.M., Karami, H., \& Khodi, A. (in press). Examination of factorial structure of Iranian English Knokur examination: An IRT analysis. Current Psychology.

Alderson, J. C., \& Wall, D. (1993). Does washback exist? Applied linguistics, 14(2), 115-129. https://doi.org/10.1093/applin/14.2.11 5.

Bailey, K. M. (1996). Working for washback: A review of the washback concept in language testing. Language testing, 13(3), 257-279. https://doi.org/10.1177/026553229601300303.

Chalhoub-Deville, M. (2016). Validity theory: Reform policies, accountability testing, and consequences. Language Testing, 33(4), 453-472.

Cheng, L., \& Falvey, P. (2000). What works? The washback effect of a new public examination on teachers' perspectives and behaviours in classroom teaching. Curriculum Forum, 9(2), 10-33.

Cheng, L. E., Watanabe, Y. E., \& Curtis, A. E. (2004). Washback in language testing: Research contexts and methods. Lawrence Erlbaum Associates Publishers. https://doi.org/10.4324/9781410609731.

Farhady, H. (1985). Evaluating English test in Iranian Konkur examination. Roshd Amozesh Zaban, 3(3), 15-17.

Farhady, H., Jafarpoor, A., \& Birjandi, P. (1994). Testing language skills: From theory to practice. SAMT Publications.

Ghorbani, M. R. (2012). Controversy over abolishing Iranian university entrance examination. Asian Education and Development Studies, 1(2), 139-152.

Ghorbani, M. R., \& Neissari, M. (2015). Washback effect of the Iranian concours on senior high school students' EFL learning activities. Iranian Journal of Language Testing, 5(1), 1-28.

Hosseini, S. M. H. (2007). ELT in higher education in Iran and India - a critical view. Language in India, 7, 1-11 Retrieved October 9, 2008, from http://www.languageinindia.com/dec2007/eltinindiaandiran.pdf.

Jahangard, A. (2007). Evaluation of the EFL materials taught at Iranian high schools. The Asian EFL Journal, 9(2), 130-150.

Khodi, A. (2020). An appraisal of validity and dimensionality of B.A. Iranian University Entrance Examination (Unpublished doctoral dissertation). University of Tehran.

Messick, S. (1989). Meaning and values in test validation: The science and ethics of assessment. Educational researcher, 18(2), 5-11. https://doi.org/10.3102/0013189X018002005.

Razmjo, S. A. (2006). Content analysis of specific questions of the English language test group of the national entrance exam of the country's universities. Shiraz University Journal of Social Sciences and Humanities, 1(46), 465-480.

Roberts, J. A., Altenberg, E. P., \& Hunter, M. (2020). Machine-scored syntax: comparison of the CLAN automatic scoring program to manual scoring. Language, Speech, and Hearing Services in Schools, 51(2), 479-493. https://doi.org/10.1044/201 9_LSHSS-19-00056.

Salehi, H., \& Yunus, M. M. (2012). The washback effect of the Iranian universities entrance exam: Teachers' insights. GEMA Online ${ }^{\oplus}$ Journal of Language Studies, 12(2), 609-628.

Salehi, M., \& Zamanian, M. (2012). The use of supplementary materials by Iranian EFL teachers at high schools for talented students. Journal of Studies in Learning and Teaching English, 1(2), 167-185.

Spratt, M. (2005). Washback and the classroom: The implications for teaching and learning of studies of washback from exams. Language teaching research, 9(1), 5-29. https://doi.org/10.1191/1362168805/r152oa.

Stobart, G. (2003). The impact of assessment: Intended and unintended consequences. Rutgers.

\section{Publisher's Note}

Springer Nature remains neutral with regard to jurisdictional claims in published maps and institutional affiliations.

\section{Submit your manuscript to a SpringerOpen ${ }^{0}$ journal and benefit from:}

- Convenient online submission

- Rigorous peer review

- Open access: articles freely available online

- High visibility within the field

- Retaining the copyright to your article

Submit your next manuscript at $\boldsymbol{\nabla}$ springeropen.com 